\title{
EL ASILO DIPLOMÁTICO Y EL CASO ALAN GARCÍA
}

\author{
DIPLOMATIC ASYLUM AND THE ALAN GARCIA CASE
}

\author{
Augusto Hernández Campos *
}

\section{Resumen}

El asilo diplomático o político constituye una institución relevante dentro del sistema universal de protección de Derechos Humanos y libertades fundamentales. Si bien se regula básicamente en América Latina, también existe cierta práctica en el resto de los países del mundo, aún cuando en principio no se le conceda reconocimiento jurídico. En este sentido, el asilo diplomático es una contribución que realiza América Latina, en el marco del Derecho Internacional Americano, a los Derechos Humanos Internacionales y al Derecho Internacional en general. Si bien se concede el asilo diplomático por motivos de persecución política, en el caso de Alan García, Uruguay ha denegado este asilo pues no existían delitos políticos. La finalidad de este artículo será presentar algunos conceptos básicos sobre el asilo diplomático y el caso de Alan García, donde fue denegado dicho asilo por tratarse de investigación por delitos comunes.

Palabras clave: Derecho de Asilo Diplomático, Derecho Diplomático, Inmunidad de Jurisdicción, Inmunidad Diplomática.

\section{Abstract}

\footnotetext{
* Doctor en Derecho y Ciencia Política, UNMSM (Universidad Nacional Mayor de San Marcos), summa cum laude, 2010. Profesor Principal de la Facultad de Derecho y Ciencia Política de la UNMSM. Catedrático de Derecho Internacional Público y Política Internacional. Profesor del Doctorado de Derecho de la UNMSM. Profesor del Doctorado y Postdoctorado del Centro de Altos Estudios Nacionales (CAEN), Lima. Profesor honorario del CAEN. Profesor de la Escuela de Relaciones Internacionales de la USIL (Universidad San Ignacio de Loyola). Miembro Titular de la Sociedad Peruana de Derecho Internacional. Miembro de la American Society of International Law y de la European Society of International Law. Es editor del Anuario Peruano de Derecho Internacional, de la Revista Peruana de Estudios del AsiaPacifico y la Revista Peruana de Ciencia Política, de la UNMSM. Ha escrito libros de su especialidad.
}

Este ensayo surgió como parte del dictado del curso de Seminario de Derechos Humanos en el Doctorado de Derecho de la UNMSM.

Dedicado al TADI, Taller de Derecho Internacional, de la Facultad de Derecho y Ciencia Política de la UNMSM, que tuve el gusto de fundar en 1997, y que es el taller integrado por alumnos interesados en temas internacionales más antiguo y más prestigioso de esta facultad. Dedicado a mis alumnos de la Escuela de Relaciones Internacionales de la USIL (Universidad San Ignacio de Loyola). 


\section{Revista Peruana de Derecho Internacional \\ Tomo LXXEnero-A6ril $2020 \mathcal{N}^{\circ} 164$, pp. 67-95. \\ ISSN: 2663-0222}

Diplomatic or political asylum is a relevant institution within the universal system of protection of human rights and fundamental freedoms. Although it is basically regulated in Latin America, there is also some practice in the rest of the world, even if in principle it is not granted legal recognition. In this sense, diplomatic asylum is a contribution made by Latin America, within the framework of International American Law, to International Human Rights and to International Law in general. Although diplomatic asylum is granted on the grounds of political persecution, in the case of Alan Garcia, Uruguay has denied this asylum as there were no political crimes. The purpose of this article will be to introduce some basic concepts about diplomatic asylum and the case of Alan Garcia, where it was denied asylum because it was an investigation for common crimes.

Keywords: Law of Diplomatic Asylum, Diplomatic Law, Jurisdiction Immunity, Diplomatic Immunity.

\section{Introducción}

El asilo diplomático o político constituye una institución relevante dentro del sistema universal de protección de Derechos Humanos y libertades fundamentales. Si bien se regula básicamente en América Latina, también existe cierta práctica en el resto de los países del mundo, aun cuando en principio no se le conceda reconocimiento jurídico. En este sentido, el asilo diplomático es una contribución que realiza América Latina, en el marco del Derecho Internacional Americano, a los Derechos Humanos Internacionales y al Derecho Internacional en general. Si bien se concede el asilo diplomático por motivos de persecución política, en el caso de Alan García, Uruguay y Costa Rica han denegado este asilo al expresidente peruano pues no existían delitos políticos.

La finalidad de este artículo será presentar algunos conceptos básicos sobre el asilo diplomático y el caso de Alan García, donde fue denegado dicho asilo por tratarse de investigación por delitos comunes.

Para cumplir con tal fin, se ha dividido el presente ensayo en varias partes. Se examinarán los siguientes temas: la definición de asilo diplomático, la evolución histórica, la diplomacia permanente, las teorías que fundamentan las inmunidades diplomáticas, la inviolabilidad del local de la misión, características del asilo diplomático, el asilo como regla latinoamericana, las fuentes del asilo diplomático, y el caso Alan García.

\section{Definición de asilo diplomático o extraterritorial}

El asilo (del latín asylum, "santuario", y este del griego asylon, "refugio") es casi tan antiguo como la civilización. Aunque en su acepción contemporánea, el asilo tal como lo conocemos ahora surge al inicio de la era moderna. 
Las expresiones Asilo Diplomático, Asilo Político y Asilo Extraterritorial se consideran como conceptos jurídicamente sinónimos. Esto se verifica en la Convención de Caracas sobre Asilo Diplomático de 1954, art. 1, cuando define el Asilo Diplomático como aquel "asilo otorgado en legaciones, navíos de guerra y campamentos o aeronaves militares". 1

Las Convenciones de 1933 (art. 1) $)^{2}$ y 1939 (art. 2) $)^{3}$ sobre Asilo Político, definen al asilo político en el mismo sentido que la Convención de Asilo Diplomático de 1954, art. 1.

Se podría definir al asilo diplomático strictu sensu como el otorgamiento de refugio a una persona perseguida a causa de motivos políticos en el local de una embajada extranjera y que es concedida por el Estado acreditante dentro del territorio del Estado receptor que es el Estado de residencia o el Estado de nacionalidad del solicitante del asilo. En sentido estricto, el asilo diplomático sería una forma de asilo extra-territorial. ${ }^{4}$

En sentido amplio, el asilo extra-territorial incluiría no solo al concedido en instalaciones diplomáticas sino también en locales militares como campamentos o aviones militares, buques de guerra, incluso buques mercantes públicos, buques privados, y locales consulares. Empero, debido a que el asilo diplomático es la principal forma practicada de asilo extraterritorial, ambos términos se han fusionado y son sinónimos jurídicamente.

El asilo extraterritorial se puede definir como la protección que otorga un Estado a un extranjero fuera de su territorio en lugares que poseen inmunidad de jurisdicción (e.g., el local de su embajada), dichos lugares están en territorio extranjero.

La controversia del asilo extraterritorial estriba en que al ejercer su autoridad un Estado en el territorio de otro Estado se considera un quebrantamiento de la soberanía territorial.

Según nos recuerda Ronning, el asilo diplomático "se aplicará solo al refugio otorgado a personas en lugares que disfruten de inmunidad diplomática de jurisdicción local. En otras palabras, es la protección otorgada al súbdito de un Estado dentro del territorio de ese Estado por el representante residente de un Estado extranjero." 5 De esta

\footnotetext{
1 Convención sobre Asilo Diplomático de Caracas de 1954, art. 1. Según el mismo artículo, "legación es toda sede de mision diplomática". Ibid.

2 Convención sobre Asilo Político de Montevideo de 1933, art. 1. El asilo político es el otorgado "en legaciones, naves de guerra, campamentos o aeronaves militares".

3 Tratado sobre Asilo Político y Refugiados de Montevideo de 1939. En el Capítulo I del Asilo Político, art. 2, define al Asilo Político como el que "solo puede concederse en las embajadas, legaciones, buques de guerra, campamentos o aeronaves militares".

$4 \mathrm{El}$ asilo extraterritorial es concedido por un Estado fuera de su territorio en locales diplomáticos, en instalaciones dependientes del Estado en el extranjero como buques de guerra, campamentos o aviones militares. El asilo diplomático, strictu sensu, solo estaría relacionado con las instalaciones diplomáticas.

${ }^{5}$ La cursiva es del autor. Vid., Carroll Neale Ronning, Diplomatic Asylum: legal norms and political reality in Latin American relations (La Haya: Nijhoff, 1965), pp 7-8.
} 
Revista Peruana de Derecho Internacional

Tomo LXXEnero-A6ril $2020 \mathcal{N}^{\circ} 164$, pp. 67-95.

ISSN: 2663-0222

manera el enfoque se limita principalmente a la protección otorgada en legaciones y embajadas, pero "La práctica es extendida a menudo a los consulados y buques públicos (y en ocasiones privados) $[\ldots]$ ". 6

Felice Morgenstern, la excepcional académica de Cambridge y recordada profesora de derecho internacional, nos proporciona su definición:

"El termino "asilo "extraterritorial"" es utilizado para indicar el asilo otorgado dentro del territorio del Estado donde se busca refugio. Se refiere al asilo en legaciones y consulados, y en buques de guerra y mercantes en los puertos del Estado del cual el individuo que busca refugio trata de escapar. A este respecto, difiere del asilo 'territorial', que es otorgado dentro del territorio del Estado que lo otorga. El asilo extraterritorial tiene lugar en perjuicio de la soberanía territorial del Estado donde se otorga. Por esto se restringe la jurisdicción del último sobre todos los individuos en su territorio, una jurisdicción que es, en virtud del derecho internacional, un atributo esencial de la soberanía del Estado. Por tanto, no es una práctica que pueda ser seguida a la ligera; su base legal debe ser establecida claramente."7

El asilo diplomático, llamado también asilo político o asilo extraterritorial, existe cuando es otorgado en embajadas, consulados, aviones militares o buques de guerra en aguas extranjeras. Debido a que su práctica ha involucrado principalmente las instalaciones de la misión diplomática permanente, como las embajadas y legaciones, es conocido comúnmente como asilo diplomático.

\section{Evolución histórica del asilo}

El asilo es una institución que nace en la Antigüedad. El asilo es una protección que otorgaba un Estado a un extranjero perseguido (asilo territorial) o las iglesias oficiales ofrecían asilo religioso (santuario) a nacionales delincuentes comunes. El asilo religioso se considera como un antecedente del asilo diplomático. ${ }^{8}$ En diversas situaciones los Estados otorgaban asilo territorial a extranjeros perseguidos políticos como Aníbal que se refugió en Siria y Bitinia (durante las Guerras Púnicas), el ex-rey de Esparta, Demarato, quien se refugió en la corte del rey de Persia, Darío I (durante las Guerras Medicas), o Eneas hallando refugio en el Lacio (huyendo de Troya).

En el Medioevo, la Iglesia Católica Romana también podía otorgar santuario. "Los lugares sagrados, en virtud de su asociación con la divinidad, vinieron a ser considerados como inviolables [...]. En consecuencia, estos lugares otorgaban asilo a los perseguidos.", recordaba Sinha. ${ }^{9}$ El derecho de santuario o asilo religioso fue abolido durante la Reforma Protestante.

${ }^{6}$ Op. cit.

7 Felice Morgenstern, "Extra-territorial' Asylum", British Yearbook of International Law, vol. 25 (1948), p. 236.

${ }^{8}$ Ambos tipos de asilo (religioso y diplomático) se otorgan en ciertos locales que gozaban de inmunidad frente a la jurisdicción territorial del Estado.

9 Prakash Sinha, Asylum and International Law (La Haya: Nijhoff, 1971), p. 5. 
El asilo en su forma actual aparece cuando surge la sociedad moderna. El asilo se otorgaba en la sociedad premoderna a aquellos que cometían los delitos comunes, y después de manera sucesiva, en la sociedad moderna, a los que cometían delitos políticos.

Los delitos comunes pueden definirse, grosso modo, como aquellos que están comúnmente sancionados en los códigos penales de todos los países del mundo, como el robo, el chantaje, el homicidio, el estupro, entre otros. En cambio, los delitos políticos son aquellos que atentan contra la vigencia del sistema político-jurídico del Estado, por lo general estos últimos delitos suceden en los sistemas autoritarios.

\subsection{El asilo ratione personae: personas protegidas}

En la Edad Antigua y en el Medioevo, el asilo se otorgaba generalmente a personas que habían cometido los delitos comunes y no a aquellos considerados los más peligrosos por los soberanos, los que cometían los llamados delitos políticos. Lo que sucede es que la represión de los delitos comunes se consideraba como materia de interés principalmente de los afectados y privados, y que la justicia penal no era una función esencial del Estado. Mientras, que el Estado debía centrarse en la represión de los delitos políticos considerados como los más peligrosos y que afectaban la autoridad del soberano.

En la Era Moderna, a partir de la Reforma Protestante se produce una inversión de los conceptos. Este cambio, en el Estado moderno, se debía a que los delitos comunes se consideraban iban en detrimento del interés público por lo que el ejercicio de la justicia penal se consideró como una función esencial del Estado. Además, se desarrolló la idea de la cooperación entre Estados para reprimir los delitos comunes mediante la extradición.

\subsection{El asilo ratione loci: lugares de protección}

En la Antigüedad (Egipto, Grecia, Roma), y el Medioevo (Res Publicae Christiana), los lugares de asilo eran: (1) los territorios de los Estados extranjeros, y (2) los templos e iglesias (i.e. los lugares considerados sagrados de las iglesias oficiales). En el Medioevo, la Iglesia Católica en virtud de este asilo podía ofrecer santuario.

En la Era Moderna, con la secularización de la sociedad moderna, el asilo religioso perdió su significado. En adelante el asilo se daría solo en los territorios de los Estados (i.e., asilo territorial). La base del asilo territorial es el principio de soberanía.

\section{Evolución de la diplomacia y la diplomacia permanente}

\subsection{La diplomacia}

La diplomacia, como instrumento de relaciones entre los gobiernos de los Estados, ha existido desde los albores de la civilización y desde la aparición de los primeros Estados en Sumeria. La primera forma histórica de diplomacia fue la itinerante (diplomacia no permanente, especial, o ad hoc, aún vigente en la actualidad). 
El fundamento para la inmunidad de estas misiones diplomáticas itinerantes era la teoría del carácter representativo (o de la representación personal). Esta teoría es la más antigua de las que explican el status de los privilegios diplomáticos. Dado que los monarcas de los países dirigían las relaciones externas, su enviado era su representante personal, a veces referido como su alter ego. En consecuencia, conforme con el axioma latino par in parem non habet imperium, ${ }^{10}$ "él no podía de forma alguna estar sujeto a la autoridad del Estado al cual él ha sido enviado como el representante personal de un monarca soberano ante otro monarca soberano."11 En otras palabras la inmunidad de un agente diplomático surgía porque éste era considerado una extensión del gobernante que le enviaba. El representante era tratado como si el mismo soberano del Estado extranjero estuviera dirigiendo las negociaciones diplomáticas.

Esto se actualiza en el principio de inmunidad de los Estados soberanos, que señala que los Estados soberanos extranjeros no están sometidos a la jurisdicción de otros Estados debido a que justamente son soberanos (principio de soberanía), lo que incluye a sus representantes oficiales, como, por ejemplo, los jefes de Estados, de gobierno, o agentes diplomáticos.

\subsection{La diplomacia permanente}

Después, de forma sucesiva y yuxtapuesta, surgen las misiones diplomáticas permanentes, con el nacimiento del Estado moderno. Entonces, se planteó la teoría extraterritorial de Hugo Grocio como fundamento de la inmunidad diplomática al respecto. Las primeras misiones diplomáticas residentes o permanentes aparecen en la Italia renacentista del siglo XV.

Esta teoría quedó sustituida por la teoría de la necesidad funcional planteada por Cornelis van Bynkershoek y después por Emmerich De Vattel en el s. XVIII. A causa del rechazo de los Estados europeos, el asilo diplomático o extraterritorial dejó de aplicarse casi completamente en Europa a inicios del siglo XIX, salvo en casos excepcionales como en disturbios políticos o guerra civiles. Como ya se indicó esta clase de asilo se consideró como perjudicial a la soberanía territorial del Estado. Asimismo, con el creciente abuso del franchise des quartiers, esta institución cayó más en el descredito, sobre todo cuando Francia en 1693 aceptó finalmente su abolición. A fines del siglo XVII, comenzó a ser cuestionado el asilo diplomático en Europa, pues los Estados le consideraban como una amenaza a su soberanía. Al término del siglo XVIII, este derecho casi desapareció en Europa.

Sin embargo, a partir de la segunda década del siglo XIX el asilo diplomático fue aceptado en América Latina, especialmente después que accedieran a la independencia los veinte Estados latinoamericanos. Esto se debía especialmente a la alta inestabilidad política que tenían los países latinoamericanos con los golpes de Estado,

\footnotetext{
10 "No tiene autoridad un igual entre iguales".

11 Vid., Stanislaw Nahlik, "Development of Diplomatic Law: selected problems", en: Academia de Derecho Internacional. Recueil des Cours, T. 222, vol. 1990-III (Dordrecht: Nijhoff, 1991), p. 221.
} 
revoluciones y guerras civiles. ${ }^{12}$ Desde los primeros tiempos de la vida republicana latinoamericana hasta mediados del siglo XIX, ya los viejos políticos derrotados acudían a las pocas y primeras legaciones o consulados extranjeros que habían sido acreditados. Poco a poco, con el paso de los años, los asilados fueron multiplicándose y las discusiones consiguientes convirtiéndose en mas agudas y mas jurídicas. ${ }^{13}$

El asilo diplomático surge cuando la Reforma Protestante, la Modernidad y la aparición del Estado moderno. El origen del asilo diplomático está estrechamente vinculado al establecimiento de misiones diplomáticas permanentes (particularmente relacionado al principio de la inviolabilidad de los locales de la misión diplomática). La diplomacia permanente (basada en misiones diplomáticas permanentes), como sabemos, es un fenómeno moderno vinculado al surgimiento del Estado moderno (después del Medioevo). El surgimiento de la diplomacia permanente condujo a la cuestión de la inviolabilidad de los locales de la misión diplomática. Con dichas misiones, también aparece la cuestión del asilo diplomático, i.e., el asilo otorgado en el local de la misión diplomática permanente.

\section{Teorías que fundamentan las inmunidades diplomáticas}

Cuando surge la diplomacia permanente, a mediados del siglo XV, surge la cuestión del otorgamiento de asilo en los locales de la misión diplomática permanente. Entonces, se examina la lógica que debe sustentar la inmunidad de la misión diplomática permanente, la cual permitirá o no el asilo diplomático, llamado también asilo extraterritorial.

Como ya se comentó antes, la primera teoría que fundamenta las inmunidades diplomáticas era la teoría representativa, y tuvo vigencia hasta fines del siglo XVIII. La segunda teoría, que es la extraterritorial, aparece con las primeras misiones diplomáticas residentes en el siglo XV y tuvo vigencia hasta inicios del siglo XX. La tercera, que es la funcional, surge en el siglo XVIII, pero se volverá la teoría suprema válida en el Derecho Diplomático en el siglo XX con la CVRD de $1961 .^{14}$

El asilo diplomático, que surge con las misiones diplomáticas permanentes en el siglo XV, tendrá vigencia hasta fines del siglo XVIII e inicios del siglo XIX, cuando desaparecerá por rechazo de los Estados europeos. Pero reaparecerá este tipo de asilo en América Latina en las primeras décadas del siglo XIX, y sigue vigente en el siglo XXI, sustentado mediante costumbre y tratados formulados por los Estados latinoamericanos.

\subsection{La teoría extraterritorial}

12 Por ejemplo, en 1836, según el connotado historiador Jorge Basadre G., Perú tenia 7 presidentes de la república a la vez. Vid., Jorge Basadre G., Historia de la República del Perú 1822-1933, t. 2 (Lima: Universitaria, [1968]), p. 160.

13 Alejandro Deustua A., "Derecho de Asilo", Revista Peruana de Derecho Internacional, t. VII, no. 23-24 (enero-junio de 1947), p. 26. Deustua publicó un amplio y destacado trabajo sobre el Derecho de Asilo en la Revista Peruana de Derecho Internacional, en los números 23-24, 25-26 (julio-diciembre 1947), 27 (enero-abril 1948), y 28 (mayo-agosto 1948).

14 Cf., Ismael Moreno Pino, La diplomacia: Aspectos teóricos y prácticos de su ejercicio profesional (México: Fondo de Cultura Económica, 2001), pp. 227-228. Para el embajador Moreno existían dos teorías adicionales: la teoría de Cecil Hurst y la del acuerdo tácito. lbid. 
El fundamento para la concesión del asilo en los locales de la misión diplomática era la teoría extraterritorial de las inmunidades diplomáticas, expuesta por Hugo Grocio en el S. XVII, que fue la primera que sustentó las inmunidades diplomáticas de las misiones diplomáticas permanentes. La teoría extraterritorial consideraba al edificio que ocupaba la embajada como territorio del Estado acreditante. Dado que, en virtud del principio de soberanía, un Estado podía otorgar asilo en su propio territorio, también podía otorgarlo en el edificio de su embajada, que era también territorio suyo. Es lo que el eminente académico polaco Stanislaw Nahlik llamó la "teoría de la inmunidad ilimitada de un enviado extranjero en el Estado receptor." 15

Pero, esta teoría, como base del status privilegiado diplomático, entra pronto en cuestionamiento. Esto sucede cuando se considera que la concesión de asilo por una embajada extranjera representaría la aplicación de la jurisdicción extraterritorial de un Estado en detrimento de la soberanía y jurisdicción territorial del Estado receptor.

Además, los abusos cometidos por las embajadas en Europa en el marco de esta teoría (así como los atropellos efectuados por las embajadas de los Estados europeos en Oriente Medio y el Imperio Otomano con las "capitulaciones", y en China mediante las "concesiones") y al amparo de esta inmunidad, sobre todo al extender esta inmunidad a todo el barrio donde está la embajada (ius quarteriorum, "ley del barrio", conocido también como franchise du quartier, que representan el mayor desprestigio para esta inmunidad, y fue una prepotencia del asilo diplomático europeo), ${ }^{16}$ se convirtieron en descrédito para esta inmunidad, pues las embajadas permitían que delincuentes comunes escaparan a la justicia (y que los extranjeros europeos en los países asiáticos se colocaran por encima de la jurisdicción territorial).

De esta manera, a inicios del siglo XIX, esta clase de asilo fue abandonada por los Estados europeos. Mientras, por otra parte, la teoría extraterritorial sería sustituida por la teoría funcional a mediados del siglo XX (planteada en el siglo XVIII por vez primera).

\subsection{La teoría de la necesidad funcional}

Cuando la teoría extraterritorial fue sustituida por la teoría de la necesidad funcional, se abandonó el fundamento jurídico del asilo diplomático o extraterritorial a mediados del siglo XX, y de este modo la regla jurídica que permitiría este asilo en adelante sería el principio de inviolabilidad del local de la misión diplomática extranjera en el marco de la teoría funcional.

En el siglo XVIII, la teoría funcional fue expuesta primero por Cornelis van Bynkershoek, y posteriormente por Emmerich De Vattel. Pero, la teoría funcional solo se volvió la teoría imperante de forma definitiva en el Derecho Diplomático con la Convención de Viena de Relaciones Diplomáticas (CVRD) de 1961.

15 Stanislaw Nahlik, op. cit., p. 223.

16 Debido a que muchas residencias diplomáticas extranjeras eran a menudo agrupadas en vecindarios, barrios o distritos, el ius quarteriorum creaba asi un área interna sujeto a la jurisdicción extraterritorial del Estado extranjero (o Estados extranjeros). 
Por tanto, con esta moderna teoría se reconoce la supremacía del principio de soberanía territorial. La soberanía sobre un territorio confiere al soberano el derecho de excluir el ejercicio de jurisdicción sobre aquel territorio por otro soberano. De este modo, se descarta el asilo diplomático o extraterritorial, pues se consideraba que este lesionaba dicha soberanía. El territorio donde se localiza la sede de la misión diplomática extranjera se considera como territorio del Estado receptor.

Esta teoría indica que un enviado debe cumplir funciones oficiales en territorio extranjero en interés de ambos Estados. Por tanto, en el Estado receptor, al enviado se le debe otorgar privilegios e inmunidades necesarios para el cumplimiento de sus funciones. Es lo que Nahlik denominó como "la teoría de la inmunidad limitada de un enviado extranjero." 17

El asilo diplomático no es regla de Derecho Internacional general y no figura en la Convención de Viena de Relaciones Diplomáticas (CVRD) de 1961. La inviolabilidad del local, que es una inmunidad básica sustentada, no en la teoría de la extraterritorialidad sino, en la necesidad de las funciones, permite el asilo diplomático.

\section{La inviolabilidad del local de la misión diplomática según la CVDR}

La inviolabilidad de los locales de la misión diplomática constituye el privilegio más importante (de los privilegios diplomáticos). El art. 22, par. 1, de la CVRD, dice: "Las instalaciones de la misión serán inviolables. Los agentes del Estado receptor no pueden entrar en ellas, excepto con el consentimiento del jefe de misión”. Es la clásica franchise d'hôtel (del francés, "inviolabilidad del local", i.e. de las instalaciones de la embajada y de la residencia privada del embajador), que nos recuerda Javier Pérez de Cuéllar. ${ }^{18}$

\section{El caso de Julian Assange}

En el caso de Julian Assange se planteó el asilo diplomático, cuando en Londres, el 16 de agosto del 2012, Ecuador anunció que otorgaría refugio a Julian Assange en el local de su embajada. Assange había entrado allí el 19 de junio anterior. Sin embargo, el Reino Unido no reconoce el asilo diplomático. Pero, las fuerzas policiales inglesas no entran en la embajada ecuatoriana debido a la inviolabilidad del local de la misma.

Cuando el nuevo gobierno de Lenin Moreno asumió el mandato en mayo del 2017 la situación cambió radicalmente, pues el nuevo presidente invitó a las fuerzas del orden británicas a entrar en el local de la misión diplomática ecuatoriana el 11 de abril del 2019, fecha en que arrestaron a Assange en una de las habitaciones de la embajada. Así, terminaron 7 años de crisis en las relaciones Ecuador-Reino Unido, por la permanencia de Assange dentro del local de la embajada ecuatoriana. Este es uno de los muy escasos casos en que el Estado acreditante levanta la inmunidad de su propia embajada frente al Estado receptor.

\footnotetext{
17 Nahlik, op. cit.

18 Javier Pérez de Cuéllar, Manual de derecho diplomático (México: Fondo de Cultura Económica, 1997), p. 89.
} 


\section{Asilo diplomático como regla latinoamericana}

Como bien nos apunta Francis Deák, "La doctrina del asilo diplomático no ha logrado una aceptación general en el derecho internacional."19 Y agrega: Durante el siglo XIX, "la práctica de conceder este asilo quedo mayormente limitada a América Latina y fue vista con malos ojos por Estados Unidos y la mayoría de los países europeos." 20

La única región en donde el asilo diplomático se mantiene como regla jurídica internacional es América Latina. El asilo diplomático sucede, principalmente, cuando el individuo busca protección en el local de una misión diplomática, siendo el caso más célebre el caso del Asilo de Haya de la Torre en 1949-1954.

Como ya se indicó, este tipo de asilo no es regla del DI general, ni la contempla la CVRD de 1961. La única concesión de esta Convención fue el art. 41, par. 3, para permitir el uso del asilo diplomático por los Estados latinoamericanos. Javier Perez de Cuellar nos remarca su exclusión de la CVRD (Convención de Viena de Relaciones Diplomáticas):
"Aunque vinculado a la inviolabilidad de los locales de las Misiones diplomáticas, este derecho no es considerado una institución de Derecho Diplomático y, en consecuencia, la Conferencia de Viena [de Relaciones Diplomáticas] de 1961 decidió no ocuparse de esa materia en su Proyecto de Convención." 21

A pesar que se considera que el asilo extraterritorial no tiene validez frente a la jurisdicción territorial, porque quebranta este principio de jurisdicción fundamental, en América Latina alcanzó la categoría de regla. Además, es un principio bien establecido de derecho internacional que los Estados pueden limitar su propia soberanía mediante tratados internacionales. Así, los Estados latinoamericanos han suscrito tratados diversos relacionados con el asilo diplomático.

La causa por la que en América Latina el asilo se ha mantenido es fundamentalmente por el hecho que los sistemas políticos estatales de la región han sido sumamente inestables. Las numerosas revoluciones y golpes de Estado en esta región convertían a los gobiernos de hoy en los perseguidos de mañana, de esta manera serían los próximos en buscar asilo.

\section{El asilo diplomático fuera de América Latina}

\footnotetext{
19 Vid., Francis Deák, "Órganos del Estado en sus relaciones exteriores: inmunidades y privilegios del Estado y de sus órganos", en: Max Sorensen (ed.), Manual de Derecho Internacional Público (México: Fondo de Cultura Económica, 1985), p. 399.

$20 \mathrm{lbid}$.

21 Javier Pérez de Cuéllar, Manual de derecho diplomático (México: Fondo de Cultura Económica, 1997), p. 118.
} 
Como se comentó antes, el asilo diplomático dejó de observarse en Europa, especialmente a partir de inicios del siglo XIX. En adelante, la concesión de lo que podría ser asilo diplomático, cuando se efectuara, se basará en consideraciones humanitarias extrajurídicas, y al no existir una práctica uniforme, no existe una costumbre respectiva. En el siglo XX, tuvo reapariciones en algunas ocasiones como la Guerra Civil Española, en ciertas situaciones de la Segunda Guerra Mundial ${ }^{22}$ y la Guerra Fría. Javier Pérez de Cuéllar, el prestigioso antiguo secretario-general de la ONU, nos recuerda que "El breve retorno del asilo en los casos mencionados adoptó en Europa la forma de refugio temporal por razones humanitarias y se valió como fundamentos de la protección de los derechos humanos y del respeto a la inviolabilidad de las Misiones por el Estado receptor." 23

Empero, algunos países, pese a que se oponen a darle la categoría de regla, debido a ciertas circunstancias especiales (básicamente por cuestiones humanitarias), la practican en diversas ocasiones. Aquí se pueden citar los casos practicados por EEUU en el célebre asilo del Cardenal Josef Mindszenty, primado de la iglesia católica húngara, en Budapest en 1956-1971, y en el caso del líder de las manifestaciones de la plaza de Tiananmen, Fang Lizhi, en Beijing en 1989-1990, entre otros.

\section{Fuentes del derecho de asilo diplomático}

El asilo diplomático sólo es reconocido como tal en el Derecho Internacional americano (i.e., latinoamericano). Si bien el reconocimiento del principio de otorgar asilo político se desarrolló en una práctica latinoamericana formando una costumbre regional, fue también reconocida en tratados. Entre las normas que regulan este tipo de asilo están las que se consignan a continuación.

El primer tratado bilateral suscrito en el hemisferio occidental que trataba el tema de regulación del asilo para perseguidos políticos fue el Tratado de No Extradición por Delitos Políticos entre México y Colombia de 1823.

\subsection{Las reglas de 1867,1898 y 1922}

La práctica del asilo diplomático revivió en América Latina a poco de producida la emancipación en la década de 1820, y adquirió al cabo de unas tres o cuatro décadas de aplicación el carácter de una institución propia del Derecho Internacional americano, según observó Llanos Mansilla. ${ }^{24}$ Las arbitrariedades y divergencias que la práctica descontrolada del asilo diplomático producía (como había sucedido en Europa antes), en un principio condujeron a los Estados latinoamericanos desde el inicio a tratar de regularlo (no a prohibirlo como sucedió en el Viejo Continente).

${ }^{22}$ Como sucedió con el asilo otorgado a judíos por misiones diplomáticas de Estados neutrales en Budapest. Fue realizado por agentes diplomáticos como Raoul Wallenberg de Suecia, Carl Lutz de Suiza, Angel Sanz-Briz de España, Carlos S. Garrido de Portugal, Angelo Rotta de la Santa Sede, y Friedrich Born del CICR), durante el holocausto perpetrado por el régimen de Ferenc Szalasi, primer ministro de Hungría y jefe de los nazis húngaros de la 23 lbid. Cruz Flechada. Irlanda no tenia relaciones diplomaticas con este pais centroeuropeo.

24 Vid., Hugo Llanos Mansilla, Teoría y práctica del derecho internacional público, t. III, La persona humana (Santiago: Editorial Jurídica, 1983), p. 413. 


\section{Revista Peruana de Derecho Internacional \\ Tomo LXXEnero-A6ril $2020 \mathcal{N}^{\circ} 164$, pp. 67-95. \\ ISSN: 2663-0222}

Así, se decidió restringir su aplicación exclusivamente al caso de los perseguidos políticos. Este esfuerzo reglamentador prosiguió, "siempre con la mira de evitar que la aplicación indiscriminada del asilo llevara al descredito y la quiebra de la institución." 25

Las Reglas que se elaboraron en las Conferencias del Cuerpo Diplomático de Lima de 1867, de La Paz de 1898, y de Asunción de 1922, eran reglas que establecían pautas para la concesión de asilo diplomático, y fueron formuladas por representantes diplomáticos de Estados latinoamericanos y de otros Estados acreditados ante los gobiernos de América Latina.

En 1867, el ministro de relaciones exteriores del Perú, con la asistencia de los agentes diplomáticos acreditados ante el gobierno peruano, convocó una conferencia en Lima con el objetivo de determinar de manera uniforme el ámbito y procedimiento para el asilo diplomático. Se contó con la oposición de ciertos delegados.

Después de la conferencia de Lima de 1867, la idea de una regulación internacional del asilo diplomático fue retomada por el Tratado de Derecho Penal Internacional de enero de 1889 adoptado por el Primer Congreso Sudamericano de Derecho Internacional Privado realizado en Montevideo. También, se revisó el tema en el proyecto de Código de Derecho Internacional Público de 1911 de Epitacio Pessoa. Según Sinha, estos documentos "reconocían el asilo diplomático de delincuentes políticos como un derecho o una tolerancia aceptados por usos, convenciones, o leyes" de Estados latinoamericanos. ${ }^{26}$ Dicho asilo podía otorgarse en legaciones, buques de guerra, campos militares, y los aviones militares (que fueron añadidos con la Convención de 1928, art. 1). Los buques mercantes fueron incluidos en esta clase de asilo por el Tratado General de Paz y Amistad entre las Republicas Centroamericanas del 20 de diciembre de 1907 (art. 10).

\subsection{EI tratado de derecho penal internacional de 1889}

El primer tratado multilateral subregional (sudamericano) que expresamente reconoce el asilo diplomático fue el Tratado sobre Derecho Penal Internacional de Montevideo de 1889. La parte relevante de este Tratado es el art. 17, que dice:

"El reo de delitos comunes que se asilase en una Legación deberá ser entregado por el jefe de ella a las autoridades locales, previa gestión del Ministerio de Relaciones Exteriores, cuando no lo efectuase espontáneamente.

Dicho asilo será respetado con relación a los perseguidos por delitos políticos, pero el jefe de la Legación está obligado a poner inmediatamente el hecho en conocimiento del Gobierno del Estado ante el cual está acreditado, quien podrá exigir que el perseguido sea puesto fuera del territorio nacional dentro del más breve plazo posible.

\footnotetext{
25 Loc. cit.

26 Vid., Prakash Sinha, Asylum and International Law (La Haya: Nijhoff, 1971), p. 28.
} 
Revista Peruana de Derecho Internacional

Tomo LXX Enero-A6ril $2020 \mathcal{N}^{\circ} 164$, pp. 67-95.

ISSN: 2663-0222

El jefe de la Legación podrá exigir, a su vez, las garantías necesarias para que el refugiado salga del territorio nacional respetándose la inviolabilidad de su persona. El mismo principio se observará con respecto a los asilados en los buques de guerra surtos en aguas territoriales."27

Este tratado tuvo vigencia para cinco Estados sudamericanos: Argentina, Bolivia, Paraguay, Perú y Uruguay.

Otro antecedente lo constituyó el Acuerdo bolivariano sobre extradición de Caracas de 1911 entre Venezuela, Colombia, Ecuador, Perú, y Bolivia. Su artículo 18 señalaba que "se reconoce la institución del asilo conforme a los principios del derecho internacional".

\subsection{Las Convenciones de 1928, 1933 y 1939}

Los 3 primeros tratados específicos sobre asilo diplomático son: la Convención sobre Asilo de La Habana de 1928, la Convención sobre Asilo Político de Montevideo de 1933, y el Tratado sobre Asilo Político y Refugiados de Montevideo de 1939 (los casos de asilo de la Guerra Civil Española contribuyeron a formular este último tratado). En el marco panamericano, se adoptaron dos tratados relativos al asilo: el de La Habana en 1928 y el de Montevideo en 1933.

La existencia y reconocimiento del asilo diplomático fue confirmado por la Convención sobre Asilo de La Habana de 1928. Esta convención codificó los principios del asilo diplomático. Prohibía el asilo diplomático a delincuentes comunes, válido solo a delincuentes políticos. Durante la VI Conferencia Internacional Americana se adoptó la Convención sobre Asilo de La Habana de 1928. El art. 1 de la Convención de La Habana prohíbe el asilo para los delincuentes comunes y sí lo permite para los delincuentes políticos. Se establece que los primeros deberán ser entregados a las autoridades territoriales, mientras que los delincuentes políticos no pueden ser entregados. A juicio de Monroy, este principio lo reconoció la Corte Internacional de Justicia en su sentencia del 13 de junio de 1951 en el caso de Asilo de Haya de la Torre, donde dijo que la entrega de delincuentes políticos no puede tener lugar ni en el caso que el asilo hubiere sido concedido de forma irregular. ${ }^{28}$ Recibió la ratificación de 15 Estados: Brasil, Colombia, Costa Rica, Cuba, Ecuador, El Salvador, Guatemala, Haití, Honduras, México, Nicaragua, Panamá, Paraguay, Perú, y Uruguay.

Durante la VII Conferencia Internacional Americana se adoptó la Convención sobre Asilo Político de Montevideo de 1933. Su contribución mas importante radica en el art. 2, que establece que la calificación del delito político le corresponde al Estado que presta el asilo, es decir, que consagra el sistema de la calificación unilateral del Estado asilante. Nos recuerda Egidio Reale, que la Convención de 1933 “contiene la estipulación conocida bajo el nombre de clausula belga que excluye de la noción de crimen político el atentado cometido contra la persona del jefe de Estado o de un miembro de su familia." ${ }^{29}$ Ha recibido la ratificación o adhesión de 16 Estados: Brasil,

${ }^{27}$ Tratado de Derecho Penal Internacional de Montevideo, art. 17.

28 Vid., Marco Monroy Cabra, Derecho Internacional Público (Bogotá: Temis, 2011), p. 685.

${ }^{29}$ Cf., Egidio Reale, "Droit d'Asile", en: Academia de Derecho Internacional, Recueil des Cours, 
Revista Peruana de Derecho Internacional

Tomo LXXEnero-A6ril $2020 \mathcal{N}^{\circ} 164$, pp. 67-95.

ISSN: $2663-0222$

Chile, Colombia, Costa Rica, Cuba, Ecuador, El Salvador, Guatemala, Haití, Honduras, México, Nicaragua, Panamá, Paraguay, Perú (la ratificó en 1960), y República Dominicana.

En el ámbito subregional del II Congreso Sudamericano de Derecho Internacional Privado celebrado en Montevideo se aprobó el Tratado sobre Asilo Político y Refugiados de Montevideo de 1939, que fue suscrito por Argentina, Bolivia, Chile, Paraguay, Perú y Uruguay. Solo fue ratificado por Paraguay y Uruguay.

\subsection{Caso de asilo de 1950}

La jurisprudencia de la CIJ en Caso del Derecho de Asilo de 1950 (Perú vs. Colombia) también trata asuntos relativos con el asilo diplomático. La sentencia de la CIJ del 20 de noviembre de 1950, la del 27 de noviembre de 1950, y la del 13 de junio de 1951 en el caso de Asilo suscitaron un amplio descontento en América Latina.

El eximio jurista uruguayo Eduardo Jiménez de Aréchaga considera que la "Convención sobre Asilo Diplomático [de 1954] constituyó la réplica que dio la Organización de Estados Americanos al erróneo fallo que dio la Corte Internacional de Justicia en el Caso Haya de la Torre en 1950." ${ }^{30}$ En el mismo sentido, el embajador Rubens Ferreira de Mello afirmó que la Corte Internacional de Justicia "demostrando un profundo desconocimiento de la institución del asilo en América, pronuncio dos sentencias al respecto [...]". ${ }^{31}$ De igual manera, nos subraya la misma opinión el embajador Geraldo Eulalio do Nascimento e Silva que dice: "La decisión de la Corte fue criticada severamente, especialmente en América Latina que evitó, después de aquella sentencia, recurrir a la Corte hasta 1984 cuando Nicaragua presentó una demanda contra los Estados Unidos." 32

En opinión de Julio Barberis el "caso de asilo diplomático más famoso en el derecho internacional es indudablemente el de Víctor Raúl Haya de la Torre, que dio lugar a tres decisiones de la Corte Internacional de Justicia. Sin embargo, el estudio de estas decisiones no se recomienda como el mejor medio de alcanzar una idea precisa de la naturaleza del asilo diplomático." 33

\subsection{La Convención de Asilo Diplomático de Caracas de 1954}

Finalmente, durante la Décima Conferencia Interamericana, se suscribió la Convención sobre Asilo Diplomático de Caracas de 1954. Este último tratado codifica la costumbre regional relativa al asilo diplomático y representa la culminación

1938 , t. 63 , p. 555.

30 Eduardo Jiménez de Aréchaga et al., Derecho Internacional Público, t. 2 (Montevideo: Fundación de Cultura Universitaria, 2008), p. 427.

31 Rubens Ferreira de Mello, Dicionário de Direito Internacional Publico (Rio de Janeiro: Iguassu, 1962), p. 209.

32 Vid., Geraldo E. do Nascimento e Silva, "Diplomatic and Consular Relations", en: M. Bedjaoui (ed.), International Law: Achievements and Prospects (París/Londres/Boston/Dordrecht: Nijhoff, 1991), p. 442.

33 Julio Barberis, "Asylum, Diplomatic", en: R. Bernhardt (ed.). Encyclopedia of Public International Law, vol. I (Amsterdam-Londres-Nueva York: North Holland, 1992), p. 282. 
del desarrollo del Derecho de Asilo Diplomático latinoamericano. Recoge también la experiencia latinoamericana frente al caso de Asilo de Haya de la Torre. Seguidamente consignamos las principales disposiciones de esta Convención.

El art. 1, como ya se indicó antes, establece los lugares donde se puede otorgar el asilo diplomático como la sede de la mision diplomática (incluía también a las residencias privadas de los jefes de misión y en los lugares habilitados para ese efecto cuando el número de asilados exceda la capacidad normal de los lugares de refugio), los campamentos militares, buques de guerra, y aviones militares.

También, indica que solo se otorgará asilo a las personas perseguidas por delitos políticos, no por delitos comunes.

El art. 2, afirma que la concesión o no de asilo es una facultad soberana del Estado. No esta obligado a concederlo, ni tiene por qué fundamentar por qué lo niega, si fuera el caso. Ergo, "el individuo no podrá reclamar si un agente diplomático se niega a asilarlo." 34

El art. 4, es una contribución extremadamente relevante, pues establece que: "Corresponde al Estado asilante la calificación de la naturaleza del delito [...]". Esta calificación unilateral permite así la supervivencia de la institución del asilo.

El art. 5, establece que el asilo solo procede en casos de urgencia (como un riesgo de linchamiento, detención ilegal, entre otros), cuya calificación corresponde al Estado asilante. Asimismo, procede por el tiempo indispensable para permitir al asilado salir al extranjero.

El art. 9, el Estado asilante recibirá los informes del Estado territorial sobre el caso, "pero será respetada su determinación de continuar el asilo o exigir el salvoconducto para el perseguido".

El art. 12, afirma que "Otorgado el asilo, el Estado asilante puede pedir la salida del asilado para territorio extranjero, y el Estado territorial está obligado a dar [...] las garantías necesarias $[\ldots]$ ”.

El art. 17, indica que una vez realizada la salida del asilado, "el Estado asilante no está obligado a radicarlo en su territorio, pero no podrá devolverlo a su país de origen sino cuando concurra voluntad expresa del asilado".

A juicio de opiniones de la doctrina colombiana, la Convención de 1954 superó en mucho las disposiciones de las convenciones anteriores. Para "Colombia [la Convencion de 1954] representó un triunfo diplomático, pues tres años después de haberse proferido el fallo de la Corte Internacional de Justicia en el caso de Haya de la Torre venían a incluirse disposiciones antes rechazadas por el mas alto tribunal de justicia." 35

${ }^{34}$ Enrique Gaviria Lievano, Derecho Internacional Público (Bogotá: Temis, 2005), p. 317.

${ }^{35}$ E. Gaviria Lievano, op. cit., p. 316. 
Esta Convención de Asilo Diplomático de 1954 tiene vigencia en la actualidad y posee 14 Estados parte. Como nos remarca Eduardo Jiménez de Aréchaga, "hay dos países que han aceptado en la práctica el ejercicio del asilo en su territorio, a pesar de que no están ligados por ninguna obligación convencional para hacerlo, que son España [...] y Portugal." 36

\subsection{El Asilo Diplomático y la CVRD de 1961}

Por otro lado, el embajador mexicano Ismael Moreno Pino nos señala muy acertadamente sobre las funciones del agente diplomático "que ofrecer asilo no es permitido, ya que ello significa una injerencia del agente diplomático en los asuntos propios del Estado territorial." 37 El solicitante de asilo debe acudir motu proprio a la sede de la mision diplomática.

Mientras que ningún articulo de la CVRD (Convención de Viena de Relaciones Diplomáticas) de 1961 trata de forma expresa y específica con el asilo diplomático, la Convención incluye dos normas que tienen un efecto directo en esta práctica, nos recuerda Paul Behrens, profesor de la Universidad de Edimburgo. ${ }^{38}$ La primera es la prohibición de interferencia en asuntos internos que se encuentra regulada en el art. 41, par. 1, que dice:

"1. Sin perjuicio de sus privilegios e inmunidades, todas las personas que gocen de esos privilegios e inmunidades deberán respetar las leyes y reglamentos del Estado receptor. Tambien están obligados a no inmiscuirse en los asuntos internos de ese Estado." 39

La obligación de no interferencia por parte de los miembros de la misión diplomática se complementa con una segunda norma que podría aplicarse para casos de asilo diplomático. El art. 41, par. 3, de la CVRD (Convención de Viena de Relaciones Diplomáticas) específicamente examina el uso de las instalaciones de la misión e indica que deben utilizarse según la CVRD y cualquier otro tratado especifico vigente:

“3. Los locales de la misión no deben ser utilizados de manera incompatible con las funciones de la misión tal como están enunciadas en la presente Convención, en otras normas del derecho internacional general o en los acuerdos particulares que estén en vigor entre el Estado acreditante y el Estado receptor." 40

Por tanto, los locales de la misión deberán ser utilizados de conformidad con la CVRD, con otras normas de DI general o con otros tratados específicos, esto ultimo

\footnotetext{
36 Vid., Eduardo Jiménez de Aréchaga, Derecho Internacional Público, t. 2 (Montevideo: Fundación de Cultura Universitaria, 2008), p. 415.

37 Ismael Moreno Pino, La diplomacia: aspectos teóricos y prácticos de su ejercicio profesional (México: Fondo de Cultura Económica, 2001), p. 302.

38 Paul Behrens, "The Law of Diplomatic Asylum: A contextual approach", Michigan Journal of International Law, vol. 35 (invierno 2014), p. 325.

39 La cursiva es nuestra. CVRD, art. 41 , par. 1.

40 La cursiva es nuestra. CVRD, art. 41 , par. 3.
} 
Revista Peruana de Derecho Internacional

Tomo LXXEnero-A6ril $2020 \mathcal{N}^{\circ} 164$, pp. 67-95.

ISSN: 2663-0222

significaría la inclusión de la Convención de Caracas de 1954, lo que permitiría el asilo diplomático. ${ }^{41}$

\section{El caso Alan García (17 de noviembre - 3 de diciembre 2018)}

\subsection{La investigacion a García y su búsqueda de asilo}

El domingo 18 de noviembre del 2018, Uruguay anunció la entrada de Alan García al local de la residencia privada del embajador de Uruguay en Lima la noche del sábado 17 solicitando asilo diplomático. Uruguay y Perú son partes de la Convención de Caracas de Asilo Diplomático de $1954 .^{42}$

El mismo sábado 17, unas horas antes, el Poder Judicial había ordenado 18 meses de impedimento de salida del país de García y después que este último dijera que no saldría del Perú. El Poder Judicial investigaba a García por delito de corrupción, por una presunta colusión agravada y lavado de activos en el caso Odebrecht en Perú.

Para todos los efectos prácticos, la residencia privada del funcionario diplomático goza de los mismos privilegios e inmunidades que el local oficial de la embajada (CVRD, art. 30, par. 1).

García era investigado por el fiscal contra el lavado de activos, José Domingo Pérez, por presuntamente haber recibido un pago de Odebrecht por US\$100.000 dólares por dictar una conferencia en Brasil, a través de un intermediario. La Fiscalía peruana había solicitado 48 horas antes esta medida de restricción (18 meses de impedimento de salida del país) contra García, en el marco de las investigaciones que se siguen en su contra por presuntamente haber favorecido a la empresa Odebrecht en la licitación del Metro 1 de Lima.

El juez Juan Carlos Sánchez, del Segundo Juzgado de Investigación Preparatoria Anticorrupción, afirmó el sábado 17 que "existen suficientes elementos de convicción" y declaró fundada la medida de restricción pedida por la fiscalía. Como consecuencia de esta medida judicial, García decidió escapar a la investigación y buscar refugio en la residencia del embajador de Uruguay.

Por otro lado, la declaración política de Alan García emitida el 21 de noviembre por intermedio de su abogado (una carta dirigida a la opinion pública donde insistío en ser víctima de una persecución política) sería una violación del art. 18 de la Convención de Caracas de 1954. Así, lo confirmaron el ex-canciller del Perú, Eduardo Ferrero Costa, y el internacionalista, Juan Velit Granda, en entrevista al diario El Comercio el 22 de noviembre del 2018.

\subsection{Negación de asilo por delitos comunes}

Conforme con la Convención de Caracas de 1954, se otorga asilo por delitos

41 Behrens, op. cit., p. 327.

42 Vid., tabla del Anexo 1, ut infra. 
Revista Peruana de Derecho Internacional

Tomo LXXEnero-A6ril $2020 \mathcal{N}^{\circ} 164$, pp. 67-95.

ISSN: 2663-0222

políticos y no por delitos comunes. Determinando si la investigación o procesamiento por delito de corrupción es delito político o común, se podrá determinar si puede recibir asilo o no.

García era investigado por el poder judicial por corrupción. Dado que la corrupción no es un delito político sino común, Uruguay negó el asilo.

En la hipótesis que Uruguay hubiera otorgado asilo, esto hubiera significado un golpe nefasto contra la lucha anti-corrupción. Esto significaría que en el futuro el Poder Judicial de Peru y de otros paises latinoamericanos no podrían investigar y procesar a ex-jefes de Estado (y otros ex funcionarios de alto nivel) por corrupción, y si lo hiciera los procesados o investigados podrían recibir refugio en Uruguay porque son perseguidos por "delitos politicos". En esta situación, si Uruguay hubiera otorgado asilo a García, pese a que se le investiga por cometer un delito común y no uno político, Perú hubiera podido solicitar a la CIJ una interpretación de la expresión "delitos políticos" del art. 1 de la Convención de 1954, y si Uruguay en este sentido habría cumplido o no con la Convención de Caracas.

\subsection{Uruguay rechaza conceder asilo a García}

El lunes 3 de diciembre del 2018, el Gobierno de Uruguay anunció que no le concedería el asilo diplomático a Alan García. El presidente de Uruguay, Tabaré Vázquez, indicó que el caso de Garcia "no es una persecución política”. Por lo que así García terminó una estadía de 16 días en la residencia del embajador uruguayo, y se invitó al nacional peruano a retirarse de la residencia del embajador, lo que se hizo, horas antes, a las 8 am de este mismo dia. ${ }^{43}$

Ya antes, el 18 de enero del 2002, Uruguay había negado asilo a dos ministros del régimen fuji-montesinista, Carlos Boloña y Alberto Bustamante, quienes alegaban persecución política, pero que enfrentaban en realidad cargos por delito de corrupción y vinculación con Vladimiro Montesinos.

\subsection{Costa Rica rechaza conceder asilo a García}

El presidente de Costa Rica, Carlos Alvarado, indicó (el mismo día 3 de diciembre del 2018 en entrevista concedida al periodista Camilo Egaña de CNN en español) que García había hecho la solicitud informal de asilo por medio de un emisario el jueves 29 de noviembre ante el encargado de negocios de la embajada de Costa Rica en Lima.

Pero, la respuesta del gobierno costarricense fue negativa. Analizando la posibilidad de otorgarle asilo a Alan García, Alvarado respondió a la pregunta formulada por Camilo Egaña:

"No. En este caso, sobre una primera comunicación, se hizo ver que la anuencia

43 CNN en español, en: https://cnnespanol.cnn.com/video/alan-garcia-tabare-vazquez-asilorechazo-uruguay-pkg-digital-original/ (fecha de consulta: 26 de diciembre del 2019). 
no está ahí presente en este momento para avanzar con esa condición, por varias condiciones que hay en el contexto, particularmente los procesos internos judiciales que se llevan en el Perú". ${ }^{4}$

El 5 de diciembre, la viceministra de Relaciones Exteriores de Costa Rica, Lorena Aguilar, señaló que no hubo solicitud formal de asilo diplomatico, pero reiteró que hubo una comunicacion informal de Garcia de pedido de asilo diplomatico, a lo que se le respondió que no sería admitido tal pedido.

\section{Intentos fallidos}

Por otro lado, en esos mismos días, según la voz autorizada de un alto diplomático peruano, viejo amigo del expresidente García, ambos discípulos de Haya de la Torre, se gestionó el asilo diplomático ante el embajador del Ecuador en una reunión en dicha embajada. Empero, los funcionarios ecuatorianos nunca respondieron a la solicitud. Frente a la falta de comunicación ecuatoriana, se buscó otra embajada.

Se intentó contactar con los funcionarios de la embajada de Chile, infructuosamente, pues dichos funcionarios evadían cualquier reunión con tal finalidad, hasta que en un contacto posterior, que se logró después de cinco intentos, aceptaron que no querían concretar tal reunión porque afirmaban no querer comprometer las relaciones con el gobierno anfitrión. Esto pese a que el asilo diplomático es aceptado y regulado por los tratados de asilo diplomático firmados por ambos paises. La idea (la de buscar asilo diplomático en otras embajadas) era tener otras alternativas de asilo en otras sedes diplomáticas en caso que fallara la primera alternativa (i.e., si Uruguay decidiera no conceder el asilo).

\section{Negación de asilo a Hinostroza}

En relación con la lucha anti-corrupción y con el asilo, en este caso asilo territorial, cabe destacar el hecho que España rechazó el 5 de diciembre del 2018 la solicitud de asilo de César Hinostroza. Hinostroza había fugado a España en octubre previo para escapar a la justicia peruana. ${ }^{45}$ En un comentario, el ex-canciller del Perú, Oscar Maúrtua de Romaña, presidente de la Sociedad Peruana de Derecho Internacional, saludó la decision del gobierno español y manifestó que esta decisión verifica la existencia en el Perú de una plena democracia así como de un estado de derecho y por ende de la separación de poderes del Estado. Agregó que dicha determinación evidencia el compromiso de la comunidad internacional en la lucha contra la corrupción y la impunidad. Asimismo, afirmó que en el Perú no habia persecución política. ${ }^{46}$

44 CNN en español, en: https://cnnespanol.cnn.com/video/asilo-politico-alan-garciaexpresidente-peruano-sot-camilo/ (fecha de consulta: 27 de diciembre del 2019).

45 RPP en: https://rpp.pe>politica>judiciales>cesar-hinostroza-espana-rechazo-la-solicitud-deasilo (fecha de consulta: 31 de diciembre del 2019). También: Peru21 en: https://peru21.pe>politica>espana-rechazo-pedido-asilo-cesar-hinostroza (fecha de consulta: 31 de diciembre del 2019).

${ }^{46}$ Declaraciones del ex-canciller Oscar Maúrtua en, https://andina.pe/agencia/noticia-rechazo- 


\section{Conclusiones}

El asilo diplomático reconocido como regla de Derecho Internacional Americano surge en el siglo XIX. El asilo diplomático si bien se desarrolló a partir de la práctica, la costumbre y los tratados regionales que regulan este tipo de asilo, el momento fundamental vino con el caso de asilo de Haya de la Torre y la jurisprudencia de la Corte Internacional de Justicia sobre dicho caso. El caso de Asilo y la jurisprudencia de la CIJ sirvieron de aliciente para formular la Convención de Caracas de 1954, que es la norma angular vigente en América Latina.

Alan García recibió una denegación a su solicitud de asilo diplomático por parte del gobierno de Uruguay debido a que dicho gobierno consideró que no es un perseguido político y al hecho que era investigado por el poder judicial, en un Estado democrático, por un delito común como es corrupción. Esa consideración también la sostuvo el gobierno de Costa Rica que de igual manera denegó la solicitud informal de asilo de García.

\section{Anexo 1: \\ Los Estados Parte de la Convención de Asilo Diplomático de Caracas de 1954}

La Convención fue adoptada por la Décima Conferencia Interamericana celebrada en Caracas el 28 de marzo de 1954. Entró en vigor el 29 de diciembre de 1954 (conforme con el art. 23 de la Convención). Tiene 14 Estados Parte.

\begin{tabular}{|c|c|c|}
\hline Estados signatarios & Firma & Ratificación o adhesión \\
\hline Argentina & 28 de marzo de 1954 & 15 de febrero de 1993 \\
\hline Bolivia & 28 de marzo de 1954 & - \\
\hline Brasil & 28 de marzo de 1954 & 25 de junio de 1957 \\
\hline Chile & 28 de marzo de 1954 & - \\
\hline Colombia & 28 de marzo de 1954 & - \\
\hline Costa Rica & 16 de junio de 1954 & 13 de enero de 1955 \\
\hline Cuba & 28 de marzo de 1954 & - \\
\hline Ecuador & 28 de marzo de 1954 & 20 de marzo de 1955 \\
\hline El Salvador & 28 de marzo de 1954 & 6 de setiembre de 1954 \\
\hline Guatemala & 28 de marzo de 1954 & 5 de marzo de 1983 \\
\hline Haití & 28 de marzo de 1954 & 18 de enero de 1955 \\
\hline Honduras & 28 de marzo de 1954 & - \\
\hline
\end{tabular}

asilo-a-cesar-hinostroza-reafirma-existencia-plena-democracia-peru-735058.aspx (fecha de consulta 15 de enero del 2020). 
Revista Peruana de Derecho Internacional

Tomo LXXEnero-A6ril $2020 \mathcal{N}^{\circ} 164$, pp. 67-95.

ISSN: 2663-0222

\begin{tabular}{|l|l|l|}
\hline México & 28 de marzo de 1954 & 25 de enero de 1957 \\
\hline Nicaragua & 28 de marzo de 1954 & - \\
\hline Panamá & 28 de marzo de 1954 & 16 de enero de 1958 \\
\hline Paraguay & 28 de marzo de 1954 & 4 de octubre de 1956 \\
\hline Perú & 22 de enero de 1960 & 21 de mayo de 1962 \\
\hline $\begin{array}{l}\text { República } \\
\text { Dominicana }\end{array}$ & 28 de marzo de 1954 & 17 de noviembre de 1961 \\
\hline Uruguay & 28 de marzo de 1954 & 6 de junio de 1967 \\
\hline Venezuela & 28 de marzo de 1954 & 15 de diciembre de $1954 *$ \\
\hline
\end{tabular}

*El depósito se realizó el 29 de diciembre de 1954.

Fuente: OEA, en: http://www.oas.org/juridico/spanish/firmas/a-46.html (fecha de consulta: 28 de diciembre del 2019). 